\title{
Client perspective assessment of women's satisfaction towards labour and delivery care service in public health facilities at Arba Minch town and the surrounding district, Gamo Gofa zone, south Ethiopia
}

\author{
Zeritu Dewana', Teshale Fikadu ${ }^{1 *}$, Abebe G/ Mariam² and Misra Abdulahi ${ }^{2}$
}

\begin{abstract}
Background: A woman's satisfaction with labour and delivery care service has a good effect on her health and subsequent utilization of the services. Thus knowledge about women's satisfaction on labour and delivery care used to enhances the services utilization. The objective of this study was to assess the satisfaction of women's towards labour and delivery care service and identify factors associated it at public health facilities in Arba Minch town and the surrounding district, Gamo Gofa zone, southern Ethiopia.

Methods: Facility based cross sectional study was conducted among women who gave birth at public health facility. A total 256 women who gave birth during the study period were included in the study. Data was collected using a structured questionnaire. Satisfaction level was measured using a 5 point- likert scale questions. Data were entered using Epi data version 3.5.1 and analyzed using SPSS 20.0 statistical software. Factor analysis was employed for likert scale questions to extract factor represented each of the scale which facilitate treatment of variable as continuous for further analysis. Bi-variate and multivariable logistic regression analysis was employed to identify association between women's satisfaction and predicator variables. Statistical significance was declared at $\mathrm{P}$ value $<0.05$ on final model. The strength of association was interpreted using the adjusted odds ratio and $95 \% \mathrm{Cl}$.

Result: This study revealed that $90.2 \%$ of women who gave birth in public health facilities were satisfied with labour and delivery care. Factors associated with women's satisfaction with labour and delivery care services include: not attending formal education $[A O R=8.00,95 \% \mathrm{Cl}=(1.52,12.27)]$ attending antenatal care four times and more $[A O R=5.00,95 \% \mathrm{Cl}=(1.76,14.20)]$ waiting below 15 minutes to be seen by health professional $[A O R=3.37$, $95 \% \mathrm{Cl}=(1.14,9.97)]$ and not paying for drugs and supplies $[\mathrm{AOR}=6.19,95 \% \mathrm{Cl}=(1.34,18.59)]$.

Conclusion: Although majority of women were satisfied with the labour and delivery service they got, their level of satisfaction was influenced by educational status, number of ANC visits, waiting time, and payment for drug and supplies. Thus, public health intervention working on improving delivery care should consider these factors.
\end{abstract}

Keywords: Delivery, Satisfaction, Arba Minch, Health service

\footnotetext{
* Correspondence: fikaduteshale1@gmail.com

${ }^{1}$ Arba Minch Health Science College, Arba Minch P.O.Box \# 55, Arba Minch,

Ethiopia

Full list of author information is available at the end of the article
} 


\section{Background}

The health of women and children remain to be the major challenges in the world, particularly in developing countries. Globally an estimated 287,000 maternal deaths occur annually, $99 \%$ of this occurs in developing countries, particularly in Sub-Saharan Africa which accounted for 56 percent of the total deaths. Of these deaths most are caused by complications during or just after delivery and the vast majority of the complications are avoidable coordinated interventions [1-3].

Ethiopia is one of the countries that have the highest maternal mortality rates in the world which is estimated to be $676 / 100,000$ live births, every 1000 live births about seven women die during pregnancy, childbirth, or within two months of birth [4].

Maternal morbidity and mortality highly decrease by safe delivery and skilled birth attendant at every birth thus women's satisfaction with the service was crucial $[5,6]$. Improving maternal health and decreasing maternal mortality fall into three prevention strategies among this strategies increasing emphasis on client satisfaction with care in order to improve clients' adherence to the service and improving labour and delivery techniques [4, 7] despite this maternal morbidity and mortality did not decrease and coverage of skilled birth attendant during labour and delivery care did not increase as required.

Satisfaction influences clients' use of health services and experience of clients in obtaining care is believed to be an important predictor of future use of services as well as to influence care-seeking behavior among others in the community [8-11]. Comprehensive knowledge about women's satisfaction by labour and delivery care in local context is vital to increase delivery service utilization, to develop new intervention strategies and strengthen the existing intervention programs to reduce maternal morbidity and mortality.

Therefore the aim of this study was to assess women's satisfaction towards labour and delivery car service and its associated factors at public health facilities in Arba Minch town and the surrounding district.

\section{Methods}

\section{Study setting}

The study was conducted in Arba Minch town and the surrounding district, Gamo Gofa zone, south Ethiopia. It is located $505 \mathrm{Km}$ south of Addis Ababa (the capital city of Ethiopia). The town and the surrounding district had a total population of 300,057 in the year 2013/14 which is projected from 2007 Ethiopia Central Statistical Agency [12]. The area has one hospital and eight health centers providing an estimated 3876 labour and delivery care services annually free of charge.

\section{Study design}

Facility- based cross sectional study was conducted from April 1 to 25, 2014.

\section{Sample size}

Sample size was calculated using Epi info version 7 assuming the proportion of women who were satisfied with delivery care service to be $82.9 \%$ taken from other study [13], confidence level of $95 \%, 5 \%$ degree of precision, and $10 \%$ for non-responses rate. The calculated sample size was 229; however, all (256) women's who gave birth at public health facilities during the study periods were included.

\section{Sampling procedure}

The sample was allocated proportionally to all public health facilities based on monthly average number of women who gave birth in each facility for the year 2012/ 2013. All women who gave birth during the study period were interviewed by considering women who refused to participate in the study as non-respondent.

\section{Data collection instrument}

Data collection instrument was a structured questionnaire. Labour and delivery care service satisfaction related questions were adopted from different literatures and presented using a 5- point likert scale (1-very dissatisfied, 2-dissatisfied, 3-neutral, 4-satisfied, and 5-very satisfied). The questionnaire was initially prepared in English and translated into local language, then translated back to English to check for consistency. The instrument was pre-tested in $5 \%$ of sample size in adjacent district public health facility. The reliability of the questionnaire checked using Cronbach's Alpha and reliability coefficient was 0.87 .

\section{Data collection}

Data were collected using structured questionnaire through face to face interview at exit with participant. The data were collected by nine data collectors who have diploma in midwifery after two days of training. Filled questionnaires were checked daily for its completeness by supervisors.

\section{Data analysis}

Data were checked for completeness, edited, coded and entered into Epi data version 3.1 and exported to SPSS 20.0 statistical software for analysis. Factor analysis was employed for likert scale questions to extract factor represented each of the scale which facilitate treatment of variable as continuous for further analysis. Assumptions were checked: Kaiser-Meyer-Olkin (KMO) measure of sampling adequacy was $>0.5$ and bartlet test of significance 
was significant at $p<0.05$. Eigen value $>1$ was taken to select components.

All variables were checked for their communality value that is proportion of the variance in the original variables that is accounted for by the factor solution at $>0.5$ and variables with $<0.5$ value were removed from analysis and the procedure was repeated again. However, in this study all communality variables fulfilled the selection criteria except one component which was excluded. Finally, variables were reduced to one component to measure client satisfaction towards delivery care service with Cronbach's Alpha (reliability coefficient) value of greater than 0.7. For the overall satisfaction level, those who were satisfied in greater or equal to factor mean score of the items were categorized under "satisfied" and those who were satisfied in less than factor mean score of the items were categorized as "un satisfied". Descriptive statistics was computed for the study variables and frequency distribution tables were used to describe most of the findings. Variables with p-value less than 0.25 in bivariate analysis were entered to multivariate logistic regression using backward stepwise methods to determine factors independently associated with women's satisfaction. Odds ratios (95\% confidence intervals) were calculated to determine the association between women's satisfaction and independent variables. Model fitness was assessed using Hosmer and Leme show test $(\mathrm{p}=$ 0.935). Results were presented using tables, figures and narratives.

\section{Ethical consideration}

The ethical clearance was obtained from Jimma University, Ethical review board. Letter of cooperation to health facility was obtained from Gamo Gofa zone health office to town and the surrounding district health office. Then letter of cooperation to the respective hospital and health centers was written by town and the surrounding district. Informed (verbal) consent was obtained from the study participants. To maximize privacy of responses, staffs were not present during data collection.

\section{Result}

A total of 256 women were participated in this study. More than three forth $(77.7 \%)$ of the women were found to be in the group $20-34$ years with the mean age of 24 ( $\mathrm{SD} \pm 5.0)$. Nearly one third $(32.8 \%)$ of the respondents have attended grade 1-8 while $(23.4 \%)$ did not have formal education. Half (50.6 \%) of the respondents were protestant by religion and majority (90.6\%) of them were married. More than half 145(55.9\%) of the participant were from urban. and 170(78.9\%) had plan to give birth at health facilities (Table 1).
Table 1 Socio demographic characteristic of the respondent, Arba Minch town and the surrounding district, Gamo Gofa zone, South Ethiopia, April, 2014

\begin{tabular}{|c|c|c|}
\hline Variable & Number & Percent \\
\hline \multicolumn{3}{|l|}{ Age of mother (in year) } \\
\hline$<20$ & 44 & 17.2 \\
\hline $20-34$ & 199 & 77.7 \\
\hline $35-49$ & 13 & 5.1 \\
\hline \multicolumn{3}{|l|}{ Educational status } \\
\hline No formal education & 60 & 23.4 \\
\hline $1-8$ & 84 & 32.8 \\
\hline $9-12$ & 38 & 14.8 \\
\hline College and university & 74 & 28.9 \\
\hline \multicolumn{3}{|l|}{ Religion of mother } \\
\hline Orthodox & 117 & 45.7 \\
\hline Protestant & 132 & 51.6 \\
\hline Muslim & 7 & 2.7 \\
\hline \multicolumn{3}{|l|}{ Marital status of mother } \\
\hline Single & 24 & 9.4 \\
\hline Married & 232 & 90.6 \\
\hline \multicolumn{3}{|l|}{ Place of resident } \\
\hline Urban & 143 & 55.9 \\
\hline Rural & 113 & 44.1 \\
\hline \multicolumn{3}{|l|}{ Family size } \\
\hline Below or equal to 5 & 201 & 78.5 \\
\hline Above 5 & 55 & 21.5 \\
\hline \multicolumn{3}{|c|}{ How did you come to this facility? } \\
\hline Planned & 170 & 78.9 \\
\hline Family/neighbor & 32 & 12.5 \\
\hline Referred from other facility & 54 & 21.1 \\
\hline
\end{tabular}

\section{Obstetric history}

More than half 144(56.3\%) of the respondent were attended the recommended antenatal care visits, 187 (73\%) had under 5 children, 237(90.6 \%) delivered by SVD, 147(57.4\%) stayed in labour for less than 12 hours and $245(95.7 \%)$ delivered alive child.

Most of the mother 174(68.0 \%) reported traveling less than one hour to get to health facility, $138(53.9 \%)$ by public transport, 145(56.6\%) delivered in hospital \& payed for drug and supply. Also majority $173(67.6 \%)$ of the respondent received care by female health professionals as, by midwifes [183(71.1\%)], 196(76.6\%) waited less than or equal to 15 mints to be seen by health care provider (Table 2).

\section{Factors associated with women's satisfaction with delivery service}

Overall women's satisfaction in this study was $90.2 \%$ with factors mean index score of $-1.67(\mathrm{SD} \pm 1)$. respondents 
Table 2 Obstetric related characteristic of the respondent, Arba Minch town and the surrounding district, Gamo Gofa zone, South Ethiopia, April, 2014

\begin{tabular}{|c|c|c|}
\hline Variable & Number & Percen \\
\hline \multicolumn{3}{|l|}{ Parity } \\
\hline One & 124 & 48.4 \\
\hline Two to five & 124 & 48.4 \\
\hline Above five & 8 & 3.1 \\
\hline \multicolumn{3}{|c|}{ Number of Under 5 children } \\
\hline One & 187 & 73.0 \\
\hline Two & 69 & 27.0 \\
\hline \multicolumn{3}{|c|}{ Last pregnancy was planned } \\
\hline Yes & 184 & 71.9 \\
\hline No & 72 & 28.1 \\
\hline \multicolumn{3}{|l|}{ Ante natal care visit } \\
\hline Less than four visit & 112 & 43.8 \\
\hline Four and more & 144 & 56.3 \\
\hline \multicolumn{3}{|l|}{ Duration of labor } \\
\hline$<12$ hour & 147 & 57.4 \\
\hline $12-24$ hours & 71 & 27.7 \\
\hline$>24$ hours & 38 & 14.8 \\
\hline \multicolumn{3}{|c|}{ Presence of support persons during labour } \\
\hline Yes & 130 & 50.8 \\
\hline No & 126 & 49.2 \\
\hline \multicolumn{3}{|l|}{ Type of delivery } \\
\hline SVD & 232 & 90.6 \\
\hline $\mathrm{C} / \mathrm{S}$ & 24 & 9.4 \\
\hline \multicolumn{3}{|l|}{ Newborn out come } \\
\hline Alive & 245 & 95.7 \\
\hline Dead & 11 & 4.3 \\
\hline \multicolumn{3}{|l|}{ Facility distance by waking } \\
\hline One hour or less & 174 & 68.0 \\
\hline One to five hours & 67 & 26.2 \\
\hline Above five & 15 & 5.9 \\
\hline \multicolumn{3}{|l|}{ Means of transportation } \\
\hline Ambulance & 58 & 22.7 \\
\hline Waking & 60 & 23.4 \\
\hline Public transportation & 138 & 53.9 \\
\hline \multicolumn{3}{|c|}{ Waiting time to see by provider } \\
\hline With in 15 minute & 196 & 76.6 \\
\hline More than 15 minute & 60 & 23.4 \\
\hline \multicolumn{3}{|c|}{ Payment for drug and supply } \\
\hline Yes & 145 & 56.6 \\
\hline No & 111 & 43.4 \\
\hline \multicolumn{3}{|l|}{ Care provider sex } \\
\hline Female & 173 & 67.6 \\
\hline Male & 83 & 32.4 \\
\hline
\end{tabular}

Table 2 Obstetric related characteristic of the respondent, Arba Minch town and the surrounding district, Gamo Gofa zone, South Ethiopia, April, 2014 (Continued)

\begin{tabular}{lcc}
\hline Place of delivery & & \\
Hospital & 145 & 56.6 \\
Health center & 111 & 43.4 \\
Care provider qualification & & \\
Doctors & 42 & 16.4 \\
Midwifery & 183 & 71.1 \\
Nurse & 20 & 7.8 \\
Other & 11 & 4.3 \\
\hline
\end{tabular}

who did not attending formal education were 8 times more likely satisfied than those attending college and university education $[\mathrm{AOR}=8.00,95 \% \mathrm{CI}=(1.52$, 12.27)]. Respondents who had four and more antenatal visits were 5 times more likely to be satisfied than their counterparts $[\mathrm{AOR}=5.00,95 \% \mathrm{CI}=(1.76$, 14.20)]. Respondents who waited below 15 minutes to be examine by health professional were 3 times more likely satisfied than those who waited more than 15 minutes $[\mathrm{AOR}=3.37,95 \% \mathrm{CI}=(1.14,9.97)$ ]. Respondents who did not pay for drugs and supplies were 6 times more likely to be satisfied compared to those paid (Table 3).

\section{Discussion}

In this study $90.2 \%$ of the respondents were satisfied towards labour and delivery care service provided. This finding is higher when compared to other studies $(82.9 \%, 61.9 \%)$ conducted in different parts of Ethiopia $[13,14]$. This difference could be due to study setting difference, more availability of health service facilities and could also be the methodological difference in which we used factor analysis to set the cutoff point for satisfaction.

Participants not attending formal educational were more likely to be satisfied than mothers attending college and university, it is true that when educational level increase awareness about delivery care increase so their expectation also become high \& not satisfied with minimum compromise to the care. This is in line with the study finding reported from Southern Ethiopia and Amhara region [13, 14] but education was not associated with client satisfaction on a study conducted in Kenya [15] this difference could be probably due to study setting in which their conduct in informal settlements.

In this study those participants attending the recommended ANC visit were more likely to be satisfied than attending less than the recommended, but ANC visit 
Table 3 Factors independently associated with client satisfaction towards delivery care service at public health facility in Arba Minch town and surrounding district, Gamo Gofa zone, South Ethiopia, April, 2014

\begin{tabular}{|c|c|c|c|c|}
\hline Variable & $\begin{array}{l}\text { Satisfied } \\
\text { No(\%) }\end{array}$ & $\begin{array}{l}\text { Unsatisfied } \\
\text { No(\%) }\end{array}$ & COR(95 \% Cl) & AOR(95 \% Cl) \\
\hline \multicolumn{5}{|l|}{ Educational status } \\
\hline No formal education & $58(96.70)$ & $2(3.30)$ & $6.77(1.47,31.09)^{a}$ & $8.00(1.51,12.27)^{a}$ \\
\hline $1-8$ & $81(96.40)$ & $3(3.60)$ & $6.30(1.73,22.91)$ & 4.36(0.99,19.28) \\
\hline $9-12$ & $32(84.20)$ & $6(15.80)$ & $0.68(0.44,3.55)$ & $1.071(0.31,3.76)$ \\
\hline College \& university & $47(23.70)$ & $27(46.60)$ & 1 & 1 \\
\hline \multicolumn{5}{|l|}{ ANC visit } \\
\hline Less than four & $95(84.80)$ & 17(15.20) & 1 & 1 \\
\hline Four and more & 136(94.40) & $8(5.60)$ & $3.04(1.26,7.34)^{a}$ & $5.00(1.76,14.20)^{a}$ \\
\hline \multicolumn{5}{|l|}{ Waiting time } \\
\hline Within 15 minit & 181(93.30) & $15(7.70)$ & $2.41(1.01,5.69)^{a}$ & $3.37(1.14,9.97)^{a}$ \\
\hline$>15 \mathrm{mint}$ & $50(83.30)$ & 10(16.70) & 1 & 1 \\
\hline \multicolumn{5}{|l|}{ Payment status } \\
\hline Yes & 123(84.80) & $22(15.20)$ & 1 & 1 \\
\hline No & 108(97.30) & $3(2.70)$ & $6.44(1.88,12.11)^{\mathrm{a}}$ & $6.19(1.34,18.59)^{a}$ \\
\hline
\end{tabular}

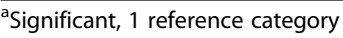

had no any association with satisfaction by the studies done in different part of Ethiopia [13, 14]. This difference could be probably due to ANC visit classification difference in this study ANC visit classified as less than four visits and four and more visits but other studies classified as attended and not attended. The level of satisfaction is also related to the payment status, nonpaying clients were more likely to be satisfied than paying clients. This is in line with a study conducted in Amhara region [14]. This may be related to the fact that their expectation free of charge for labour and delivery car at public health facilities decrease worries about their economic status difference which may increase the satisfaction level.

Association with waiting time to be seen by health care provider were those wait less than 15 minutes were more satisfied than those waiting for longer time which is consistent with studies conducted in Ethiopia, Uganda \& Bangladesh $[8,14,16]$ which is encouraging.

\section{Conclusion}

In this study educational status, number of antenatal care visits, waiting time to be examined by health providers and payment for drugs and supplies for labour and delivery care were independently associated with level of mother's satisfactions towards delivery care. Thus, intensifying intervention programmer and stakeholder working on labour and delivery care practice should focus on these determinants to reduce maternal mortality and morbidity and realize millennium development goals.

\section{Competing interests}

The authors declare that they have no competing interests.

\section{Authors' contributions}

ZD involved from the inception to design, acquisition of data, analysis and interpretation, drafting the manuscript, FT involved in the inception to design, analysis and interpretation and revises the manuscript, MA involved in the inception to design, analysis and interpretation and revises the manuscript, AGM involved in the inception to design, analysis and interpretation and revises and edits the manuscript for the final submission. All authors read and approved the final manuscript.

\section{Acknowledgements}

We would like to extend our deepest gratitude to the Jimma University College of public health and medical sciences, Department of population and family health instructors for their support and constructive comment. Also we would like to acknowledge Arba Minch collage of health science for the support. Our appreciation goes to the data collectors and supervisors. Lastly, our special thanks also go to mothers who participated in the study.

\section{Author details}

${ }^{1}$ Arba Minch Health Science College, Arba Minch P.O.Box \# 55, Arba Minch Ethiopia. ${ }^{2}$ College of Public Health and Medical Sciences, Department of population and family health, Jimma University, Jimma P.O.Box \# 230, Jimma, Ethiopia.

Received: 16 April 2015 Accepted: 2 February 2016

Published online: 11 February 2016

\section{References}

1. United Nations (UN). The Millennium Development Goal Report 2011, New York: United Nations; 2011.

2. WHO, UNICEF, UNFPA, World Bank. Trends in Maternal Mortality: 1990 to 2010. Geneva: WHO; 2012.

3. Filippi V, Ronsmans C, Campbell OMR, Graham WJ, Mills A, Borghi J, et al. Maternal health in poor countries: the broader context and a call for action. Lancet. 2006;368:1535-41.

4. Central Statistical Agency (CSA) and ICF international. Ethiopia Demographic and Health Survey 2011. Addis Ababa, Ethiopia: CSA and ICF international; 2012 
5. Mozlan J, Ortayli N, Social science Research initiative on quality of Care. An evaluation of quality of Maternity care in three Istanbul Updated January. 2002.

6. World Health Organization (WHO). Making Pregnancy Safer: The Critical Role of the Skilled Attendant. Geneva: World Health Organization; 2004.

7. World Health Organization (WHO). Beyond the Numbers: Reviewing Maternal Deaths and Complications to Make Pregnancy Safer. Geneva: World Health Organization; 2004.

8. Kiguli J, Elizabeth E, Okui O, Mutebi A, Hayley M, William G. Increasing access to quality health care for the poor: Community perceptions on quality care in Uganda. PPA. 2009;3:77-85.

9. Lilian T, Karen M, Abu M, Bjorg E, Thecla W. Why give birth in health facility? Users' and providers' accounts of poor quality of birth care in Tanzania, BMC Health Serv Res. 2013;13(174):2-12.

10. Maman D, Pierre F. Human resources and the quality of emergency obstetric care in developing countries: a systematic review of the literature. Hum Resour Health. 2009;7(7):1-12.

11. Creel L, Sass J, Yinger N. Overview of quality of care in reproductive health: definitions and measurements of quality, Population Council and Population Reference Bureau. New Perspect Qual Care, 2002;1:1-10.

12. Democratic Republic of Ethiopia/Population Census Commission (FDRE/ PCC). Summary and Statistical Report of the 2007 Population and Housing Census: Population Size by Age and Sex. Addis Ababa, Ethiopia: FDRE/PCC 2008.

13. Bereket $Y$, Mulat T, Wondimagegn P. Mothers" Utilization of antenatal care and their satisfaction with delivery services in selected public health facilities of Wolaita Zone, Southern Ethiopia. Int J Sci Technol Res. 2013;2(2):74-85.

14. Azmeraw T, Desalegn Z, Yigzaw K. Mothers' satisfaction with referral hospital delivery service in Amhara Region, Ethiopia. BMC Pregnancy Childbirth. 2011;11(78):1-7.

15. Eva SB, Michael AK. Women's satisfaction with delivery care in Nairobi's informal settlements. International J Qual Health Care. 2009:21(2):79-86.

16. Jorge MA, Helga P, Ahmed A. Client satisfaction and quality of health care in rural Bangladesh. Bull World Health Organ. 2001;79(6):512-7.

\section{Submit your next manuscript to BioMed Central and we will help you at every step:}

- We accept pre-submission inquiries

- Our selector tool helps you to find the most relevant journal

- We provide round the clock customer support

- Convenient online submission

- Thorough peer review

- Inclusion in PubMed and all major indexing services

- Maximum visibility for your research

Submit your manuscript at www biomedcentral.com/submit

C Biomed Central 